\title{
Chitosan Can Induce Rosa roxburghii Tratt. against Sphaerotheca sp. and Enhance Its Resistance, Photosynthesis, Yield, and Quality
}

\author{
Jiaohong Li ${ }^{1}$, Zhenxiang Guo ${ }^{2}$, Yue Luo ${ }^{2}$, Xiaomao $\mathrm{Wu}^{2, *}$ and Huaming An ${ }^{3, *}$ \\ 1 College of Forestry, Guizhou University, Guiyang 550025, China; xhli@gzu.edu.cn \\ 2 Institute of Crop Protection, College of Agriculture, Guizhou University, Guiyang 550025, China; \\ zhenxiangguo@126.com (Z.G.); ly721214@126.com (Y.L.) \\ 3 Research Center for Fruit Tree Engineering and Technology of Guizhou Province, Guiyang 550025, China \\ * Correspondence: xmwu@gzu.edu.cn (X.W.); anhuaming@hotmail.com (H.A.)
}

check for updates

Citation: Li, J.; Guo, Z.; Luo, Y.; Wu, X.; An, H. Chitosan Can Induce Rosa roxburghii Tratt. against Sphaerotheca sp. and Enhance Its Resistance, Photosynthesis, Yield, and Quality. Horticulturae 2021, 7, 289. https:// doi.org/10.3390/horticulturae7090289

Academic Editor: Othmane Merah

Received: 15 August 2021

Accepted: 3 September 2021

Published: 6 September 2021

Publisher's Note: MDPI stays neutral with regard to jurisdictional claims in published maps and institutional affiliations.

Copyright: (c) 2021 by the authors. Licensee MDPI, Basel, Switzerland. This article is an open access article distributed under the terms and conditions of the Creative Commons Attribution (CC BY) license (https:/ / creativecommons.org/licenses/by/ $4.0 /)$.

\begin{abstract}
Powdery mildew caused by Sphaerotheca sp. is the most serious disease of Rosa roxburghii cultivation. In this study, the foliar application of chitosan induced Rosa roxburghii Tratt. against Sphaerotheca sp. and its effects on the disease resistance, growth, yield, and quality of R. roxburghii were investigated. The results show that the foliar application of 1.0 1.5\% chitosan could effectively control Sphaerotheca sp. of $R$. roxburghii with the inducing control efficacy of $69.30 \sim 72.87 \%$. The foliar application of $1.0 \sim 1.5 \%$ chitosan significantly $(p<0.01)$ increased proline, soluble sugar, flavonoids, superoxide dismutase (SOD), and polyphenoloxidase (POD) activities of the R. roxburghii leaf and decreased its malonaldehyde (MDA), as well as reliably enhanced its photosynthetic rate and chlorophyll. Moreover, the foliar application of 1.0 1.5\% chitosan notably improved single fruit weight, yield, vitamin C, soluble solid, soluble sugar, total acidity, soluble protein, flavonoids, and SOD activity of $R$. roxburghii fruits. This study highlights that chitosan can be used as an ideal, efficient, safe, and economical inductor for controlling powdery mildew of $R$. Roxburgh and enhancing its resistance, growth, yield, and quality.
\end{abstract}

Keywords: chitosan; Rosa roxburghii Tratt.; Sphaerotheca sp.; disease resistance; yield and quality

\section{Introduction}

Rosa roxburghii Tratt., a Rosaceae deciduous shrub, is rich in antioxidants and nutrients, such as vitamin C, flavonoids, superoxide dismutase (SOD), and various minerals [1-3]. Due to its high nutritional and medical value, it is widely used in improving immunity, lowering blood pressure, regulating the digestive system, protecting the liver, as well as anti-oxidation, anti-cancer, antibacterial, and anti-radiation, etc. [4-8]. As a promising fruit crop and natural medicine, $R$. roxburghii is widely planted in Southwest China, especially in Guizhou Province. Recently, Guizhou's R. roxburghii industry has developed rapidly and made great contributions to rocky desertification control, poverty alleviation, and rural revitalization, and its planting area reached $170,000 \mathrm{hm}^{2}$ in 2020 [3,9]. However, as commercial cultivation of $R$. roxburghii expanded, many pests became increasingly serious such as Sphaerotheca sp., Grapholita molesta, and Cercospora insulana Sacc, which seriously affect the yield and quality of $R$. roxburghii and frequently cause great economic losses.

Powdery mildew caused by Sphaerotheca sp. is the most serious disease of $R$. roxburghii cultivation, which mainly damages the fresh young leaves and shoots of $R$. roxburghii, as well as flower buds, flowers, and young fruits [10]. According to the statistics, Sphaerotheca sp. seriously affects the growth, yield, and quality of $R$. roxburghii, as well as often causes 30 40\% economic losses in Guizhou Province of Southwest China. At present, chemical fungicides such as triadimefon, myclobutanil, azoxystrobin, and tebuconazole are still the predominant measures to control Sphaerotheca sp. of $R$. roxburghii [11]. Nonetheless, these 
chemicals easily generate resistance to pathogens, and their residuals negatively affect the environment, wildlife, and human beings [12-14]. Thus, it is of great significance to develop the green, efficient, safe, and economical control practice of Sphaerotheca sp. for the sustainable development of the Rosa roxburghii industry.

Inducing resistance, a newly rising agricultural practice is often activated by various biotic and abiotic inductors and plays an important role in plant adaptation to stress [15,16]. Recently, it has gained popularity as an environmentally friendly approach for controlling crop diseases. For example, Yan et al. [17] reported that $6 \%$ ascorbic acid aqueous solutions could induce systemic resistance and enhance the ability to resist Sphaerotheca sp. in $R$. roxburghii with the inducing effect of $61.45 \%$. Chitosan, a natural de-acetylated chitin derivative, is an ideal resource for sustainable agriculture due to its bioactivity, biocompatibility, biodegradability, non-toxicity, and renewability [18-20]. A wide range of studies shows that chitosan can be used as a resistance inductor and bio-fungicide for controlling plant diseases and as a growth promoter for enhancing plant development [21-26]. In the control of plant diseases, chitosan induces morphological changes and structural alterations in fungal cells that cause cell death $[20,27]$. When chitosan is used to improve plant defense, it induces resistant enzymes, pathogenesis-related proteins, phytoalexins, callose formation, and promotes lignification $[20,28]$. Up to date, however, there is no attention or documentation available about whether chitosan induces resistance of $R$. roxburghii to Sphaerotheca sp. and promotes its growth.

In this study, the inducing control efficacy of chitosan against Sphaerotheca sp. of $R$. roxburghii was firstly evaluated. Moreover, the effects of chitosan on the disease resistance, photosynthesis, yield, and quality of $R$. roxburghii were also investigated. This work provides a green, effective, safe, and economical approach for controlling Sphaerotheca sp., inducing disease resistance and promoting the growth, yield, and quality of $R$. roxburghii.

\section{Materials and Methods}

\subsection{Materials}

Chitosan (deacetylation $\geq 90.00 \%$ ) was provided by Huarun Bioengineering Co., Ltd. (Zhenzhou, China). Trees of $R$. roxburghii ‘Guinong 5' with 6-year-old were used as materials, and their planting density was 106 plants per $666.7 \mathrm{~m}^{2}$.

\subsection{Field Site}

Field experiments were conducted in 2019 in an R. roxburghii orchard at Chaxiang village, Gujiao Town, Longli country, Guizhou Province, China (26 $\left.54^{\prime} 36^{\prime \prime} \mathrm{N}, 106^{\circ} 95^{\prime} 13^{\prime \prime} \mathrm{E}\right)$. The mean altitude, mean temperature, frostless season, annual rainfall, and annual sunshine duration of the $R$. roxburghii orchard were about $1384 \mathrm{~m}, 13.9^{\circ} \mathrm{C}, 280$ days, $1100 \mathrm{~mm}$, and $1265 \mathrm{~h}$, respectively. The loam soils of the $R$. roxburghii orchard had $12.78 \mathrm{~g} \cdot \mathrm{kg}^{-1}$ of organic matter, $56.02 \mathrm{mg} \cdot \mathrm{kg}^{-1}$ of available nitrogen, $4.07 \mathrm{mg} \cdot \mathrm{kg}^{-1}$ of available phosphorus, $25.35 \mathrm{mg} \cdot \mathrm{kg}^{-1}$ of available potassium, $18.53 \mathrm{cmol} \cdot \mathrm{kg}^{-1}$ of exchangeable calcium, $317.58 \mathrm{mg} \cdot \mathrm{kg}^{-1}$ of exchangeable magnesium, $6.31 \mathrm{mg} \cdot \mathrm{kg}^{-1}$ of available iron, $15.16 \mathrm{mg} \cdot \mathrm{kg}^{-1}$ of available manganese, $0.43 \mathrm{mg} \cdot \mathrm{kg}^{-1}$ of available copper, $0.56 \mathrm{mg} \cdot \mathrm{kg}^{-1}$ of available zinc, $0.13 \mathrm{mg} \cdot \mathrm{kg}^{-1}$ of available boron, and $6.89 \mathrm{of} \mathrm{pH}$ value.

\subsection{Field-Inducing Control Experiment of Sphaerotheca sp. in R. roxburghii}

The spraying chitosan method was used for conducting the field-inducing control experiment of Sphaerotheca sp. in R. roxburghii. Four treatments were designed with $0 \%$, $0.5 \%, 1.0 \%$, and $1.5 \%$ chitosan dilution liquid, respectively. A total of twelve plots were arranged randomly with four replicates, each plot had nine trees, and a $3.5 \mathrm{~m}$ isolation area was set among plots. Five trees on the diagonal of each plot were used for determination. Soil, plant size, and tree strength in all plots were similar. Due to Sphaerotheca sp. mainly damages too fresh young leaves and shoots of $R$. roxbkurghii, as well as flower buds, flowers, and young fruits. Thus, the experiment was carried out by spraying chitosan solution 
twice, and about $1.50 \mathrm{~L}$ of chitosan dilution liquid was sprayed on each $R$. roxburghii plant (including flower, bud, leaf, and stem) on 1 April and 1 May, respectively.

2.4. Determination of Chitosan Control Effect against Sphaerotheca sp., and Resistance Parameters, Photosynthetic Rate and Chlorophyll of R. roxburghii Leaves

Late May to early June is a more serious time of Sphaerotheca sp.; thus, the inducing control effect of chitosan against Sphaerotheca sp., as well as the photosynthetic rate, chlorophyll, and resistance parameters of the leaf of $R$. roxburghii, were investigated on 1 June 2019. The incidence rate, disease index, and control effect of chitosan against Sphaerotheca sp. of $R$. roxburghii were investigated according to Equations (1)-(3), respectively. The grading standard of the incidence degree: $0=$ no incidence; $1=1 \sim 2$ diseased lobules with thin hyphae; $2=3 \sim 4$ diseased lobules with thick hyphae; $3=5 \sim 6$ diseased lobules with dense hyphae; $4=$ more than 7 diseased lobules with dense hyphae.

Incidence rate $(\%)=100 \times$ Number of disease leaves/Total number of leaves

Disease index $=100 \times \sum($ Disease grade value $\times$ Number of leaves within each grade $) /$

(Total number of leaves $\times$ the highest grade)

Control effect $(\%)=100 \times($ Disease index of control - Disease index of treatment $) /$ Disease index of control

The resistance parameters of $R$. roxburghii leaves, including proline, soluble sugar, MDA, flavonoids, SOD, and PPO activities, were determined as described by Zhang et al. [29,30]. Proline, soluble sugar, MDA, and flavonoids were analyzed by ninhydrin colorimetry, thiobarbituric acid, anthrone colorimetric, and $\mathrm{HCl}$-methyl alcohol methods, respectively. SOD and PPO activities were analyzed by the nitrogen blue tetrazole and catechol methods, respectively. The photosynthetic rate (Pn) of leaves in R. roxburghii was determined by a portable LI-6400XT photosynthesis measurement system (LI-COR Inc., Lincoln, NE, USA) at 8:00-10:00 a.m. on 1 June 2019. Chlorophyll a and chlorophyll b content of $R$. roxburghii leaves were measured by a UV-5800PC spectrophotometer at $645 \mathrm{~nm}\left(\mathrm{OD}_{645}\right)$ and $663 \mathrm{~nm}\left(\mathrm{OD}_{663}\right)$ with an acetone-ethanol $(v / v, 2: 1)$ extraction, respectively [29].

\subsection{Determination of Yield and Quality of R. roxburghii}

Fruits from each plot were randomly collected on 1 September 2019, and single fruit weight, fruit yield per plant, and fruit quality of $R$. roxburghii were subsequently determined. Single fruit weight and fruit yield per plant were determined by the weighing method. Fruit quality parameters of $R$. roxburghii such as vitamin C, soluble solid, soluble sugar, total acidity, soluble protein, flavonoids, and SOD activity were also measured according to Zhang et al. [29,30].

\subsection{Statistical Analyses}

Data were exhibited as mean \pm standard deviation (SD) of three replicates, and all analyses were carried on SPSS 18.0 (SPSS Inc., Chicago, IL, USA). A one-way analysis of variance (ANOVA) was used for determining the difference significances. Origin 10.0 was used to draw the chart.

\section{Results}

\subsection{Field-Inducing Control Effect of Chitosan against Sphaerotheca sp. of $R$. roxburghii}

As shown in Table 1, 0.5 1.5\% chitosan significantly $(p<0.01)$ reduced the incidence rate and disease index of Sphaerotheca sp. of $R$. roxburghii. The inducing control effect of $1.5 \%$ chitosan against Sphaerotheca sp. was $72.87 \%$, which was significantly $(p<0.05)$ higher than $69.30 \%$ of $1.0 \%$ chitosan and significantly $(p<0.01)$ higher than $48.12 \%$ of $0.5 \%$ chitosan. However, the incidence rate, disease index, and control effect were not significant between $1.0 \%$ chitosan and $1.5 \%$ chitosan treatments. The present results indicate that $1.0 \sim 1.5 \%$ chitosan had a suitable inducing control effect against Sphaerotheca sp. in R. roxburghii. 
Table 1. The inducing control effects of chitosan against Sphaerotheca sp. of R. roxburghii.

\begin{tabular}{cccc}
\hline Chitosan (\%) & Incidence Rate (\%) & Disease Index & Control Effect (\%) \\
\hline 0 & $48.15 \pm 6.42^{\mathrm{aA}}$ & $13.39 \pm 1.00^{\mathrm{aA}}$ & \\
0.5 & $29.63 \pm 6.41^{\mathrm{bB}}$ & $6.88 \pm 0.36^{\mathrm{bB}}$ & $48.12 \pm 5.75^{\mathrm{cB}}$ \\
1.0 & $18.52 \pm 6.41^{\mathrm{cC}}$ & $4.08 \pm 0.09^{\mathrm{cC}}$ & $69.30 \pm 1.49^{\mathrm{bA}}$ \\
1.5 & $14.81 \pm 6.41^{\mathrm{dC}}$ & $3.60 \pm 0.14^{\mathrm{cC}}$ & $72.87 \pm 2.88^{\mathrm{aA}}$ \\
\hline
\end{tabular}

Values indicate the mean \pm SD of three replicates. Different small and capital letters indicate significant differences at $5 \%$ level $(p<0.05)$ and $1 \%$ level $(p<0.01)$, respectively.

The inducing control effect of chitosan against Sphaerotheca sp. increased gradually with the increase in chitosan concentration.

\subsection{Effects of Chitosan on Proline, Soluble Sugar, Malonaldehyde, Flavonoids, SOD, and PPO Activity of R. roxburghii Leaves}

The effects of chitosan on the proline, soluble sugar, MDA, flavonoids, SOD, and PPO activities of leaves in R. roxburghii are shown in Figure 1. A total of 1.0 1.5\% chitosan significantly $(p<0.01)$ increased proline, soluble sugar, and flavonoids of $R$. roxburghii leaves compared with non-sprayed chitosan and decreased its MDA content. A total of $0.5 \sim 1.5 \%$ chitosan significantly $(p<0.01)$ enhanced SOD and PPO activities of leaves in $R$. roxburghii. Proline and soluble sugar are important substances to maintain the strong permeability of various organs. Chitosan effectively increased proline and soluble sugar of leaves in $R$. roxburghii (Figure 1a,b). MDA reflects the intensity of membrane lipid peroxidation and the damage degree of the membrane system, and flavonoids are an important disease-resistant substance. A total of 1.0 1.5\% chitosan significantly $(p<0.01)$ reduced the MDA content of leaves in R. roxburghii and increased its flavonoids (Figure 1c,d), which promoted the healthy growth and disease resistance of the $R$. roxburghii plants. SOD and PPO are important defense enzymes associated with disease resistance in plants. Chitosan significantly $(p<0.01)$ enhanced SOD and PPO activities of leaves in R. roxburghii (Figure 1e,f), which improved the disease resistance of $R$. roxburghii plants. These findings here emphasize that $1.0 \sim 1.5 \%$ chitosan could effectively improve the stress resistance of $R$. roxburghii and promote its healthy growth.

\subsection{Effects of Chitosan on Photosynthetic Rate and Chlorophyll Content of R. roxburghii Leaves}

As exhibited in Figure 2, 0.5 1.5\% chitosan effectively enhanced the photosynthetic rate of leaves in $R$. roxburghii compared with the control. The photosynthetic rate of leaves in $R$. roxburghii increased gradually with the increase in chitosan concentration. A total of $1.0 \sim 1.5 \%$ chitosan-treated plants possessed a superior photosynthetic rate of leaves in $R$. roxburghii with $6.63 \sim 7.46 \mu \mathrm{mol} \cdot \mathrm{CO}_{2} \cdot \mathrm{m}^{-2} \cdot \mathrm{s}^{-1}$, which was significantly $(p<0.01)$ higher than $0.5 \%$ chitosan and control. Moreover, $0.5 \%$ chitosan exhibited a relatively inferior photosynthetic rate of leaves in $R$. roxburghii with $5.46 \mu \mathrm{mol} \cdot \mathrm{CO}_{2} \cdot \mathrm{m}^{-2} \cdot \mathrm{s}^{-1}$, which was significantly $(p<0.05)$ higher than non-spray chitosan. The results here indicate that $1.0 \sim 1.5 \%$ chitosan enhanced the photosynthesis of the R. roxburghii plant and promoted its growth.

As revealed in Table 2, 1.0 1.5\% chitosan could significantly $(p<0.05)$ increase the content of chlorophyll $\mathrm{a}$, chlorophyll $\mathrm{b}$, and chlorophyll $\mathrm{a}+\mathrm{b}$ of leaves in $R$. roxburghii compared with control. While $0.5 \%$ chitosan exhibited a relatively inferior enhancing potential for chlorophyll of leaves in $R$. roxburghii, and the difference between it and nonspray chitosan did not reach a significant level. Chlorophyll $\mathrm{a} / \mathrm{b}$ value can reflect the preference of plants to light. Generally, the greater chlorophyll $\mathrm{a} / \mathrm{b}$ value, the more plants like light and the stronger plants have stress resistance. A total of $1.0 \sim 1.5 \%$ chitosan could significantly $(p<0.05)$ increase chlorophyll a/b value of leaves in $R$. roxburghii compared with $0.5 \%$ chitosan and non-spray chitosan. The present findings show that $1.0 \sim 1.5 \%$ chitosan increased the chlorophyll of $R$. roxburghii, thereby enhancing its photosynthesis and stress resistance. 

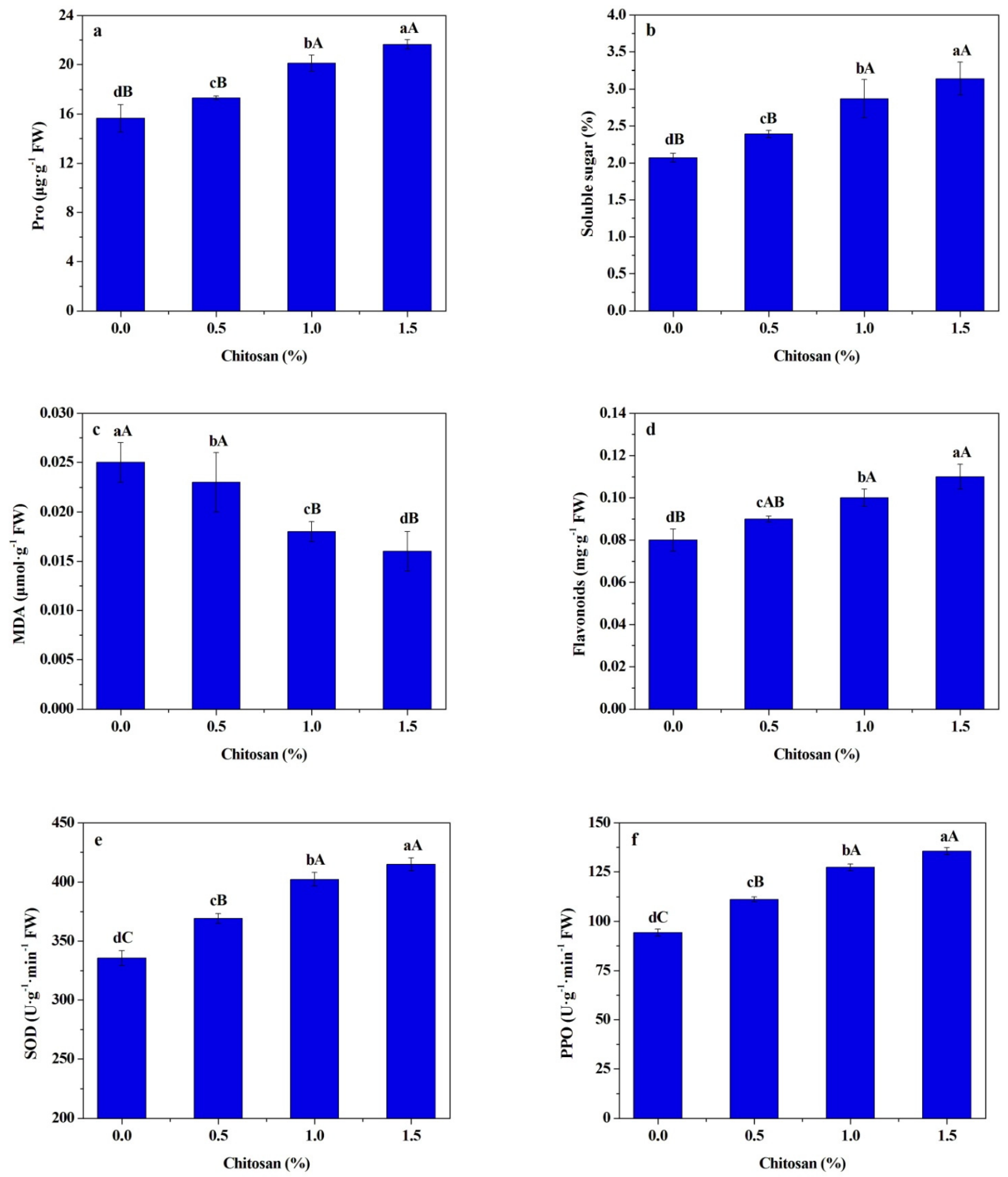

Figure 1. The effects of chitosan on the proline (a), soluble sugar (b), malonaldehyde (c), flavonoids (d), SOD activity (e), and PPO activity (f) of leaves in R. roxburghii. Values and error bars indicate the mean and SD of three replicates, respectively. Different small and capital letters indicate significant differences at $5 \%$ level $(p<0.05)$ and $1 \%$ level $(p<0.01)$, respectively. 


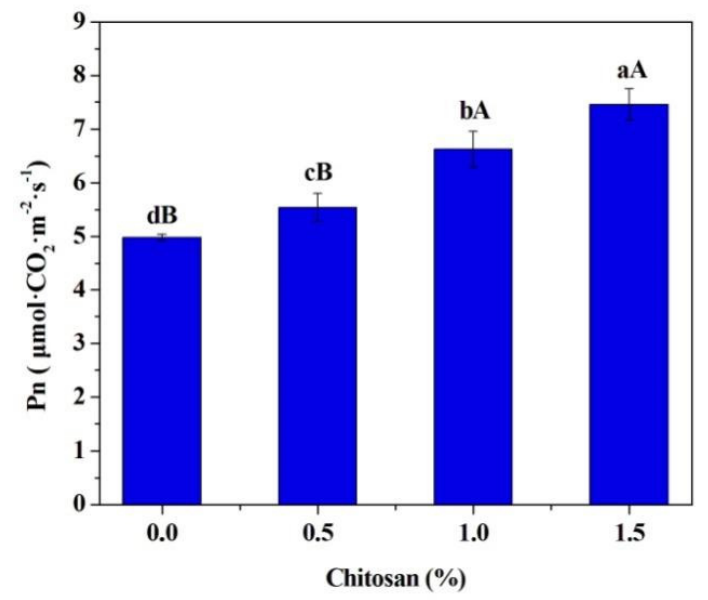

Figure 2. The effects of chitosan on the photosynthetic rate of leaves in R. roxburghii Values and error bars indicate the mean and SD of three replicates, respectively. Different small and capital letters indicate significant differences at $5 \%$ level $(p<0.05)$ and $1 \%$ level $(p<0.01)$, respectively.

Table 2. The effects of chitosan on the chlorophyll content of leaves in R. roxburghii.

\begin{tabular}{ccccc}
\hline Chitosan (\%) & Chlorophyll a & Chlorophyll b & Chlorophyll $\mathbf{a}+\mathbf{b}$ & Chlorophyll $\mathbf{a} / \mathbf{b}$ \\
\hline 0 & $2.87 \pm 0.29^{\mathrm{bB}}$ & $2.07 \pm 0.06^{\mathrm{bA}}$ & $1.38 \pm 0.10^{\mathrm{bA}}$ & $4.94 \pm 0.35^{\mathrm{bcA}}$ \\
0.5 & $3.03 \pm 0.10^{\mathrm{bB}}$ & $2.15 \pm 0.05^{\mathrm{bA}}$ & $1.41 \pm 0.08^{\mathrm{abA}}$ & $5.18 \pm 0.06^{\mathrm{bA}}$ \\
1.0 & $3.35 \pm 0.20^{\mathrm{aA}}$ & $2.32 \pm 0.03^{\mathrm{aA}}$ & $1.45 \pm 0.08^{\mathrm{aA}}$ & $5.66 \pm 0.21^{\mathrm{aA}}$ \\
1.5 & $3.49 \pm 0.18^{\mathrm{aA}}$ & $2.38 \pm 0.05^{\mathrm{aA}}$ & $1.46 \pm 0.10^{\mathrm{aA}}$ & $5.87 \pm 0.16^{\mathrm{aA}}$ \\
\hline
\end{tabular}

Values indicate the mean \pm SD of three replicates. Different small and capital letters indicate significant differences at $5 \%$ level $(p<0.05)$ and $1 \%$ level $(p<0.01)$, respectively.

\subsection{Effects of Chitosan on Yield and Quality of R. roxburghii}

The effects of chitosan on the single fruit weight and fruit yield of $R$. roxburghii are shown in Figure 3. Chitosan significantly $(p<0.01)$ increased the single fruit weight and fruit yield of $R$. roxburghii. The single fruit weight and fruit yield per plant of $R$. roxburghii treated by $0.5 \sim 1.5 \%$ chitosan were $17.38 \sim 20.68 \mathrm{~g}$ and $5.87 \sim 7.38 \mathrm{~kg}$, which significantly $(p<0.01)$ increased by 1.20 1.43 folds and 1.31 1.64 folds compared to control, respectively. The results presented here reveal that the suitable concentration of chitosan significantly enhanced fruit growth and yield formation.
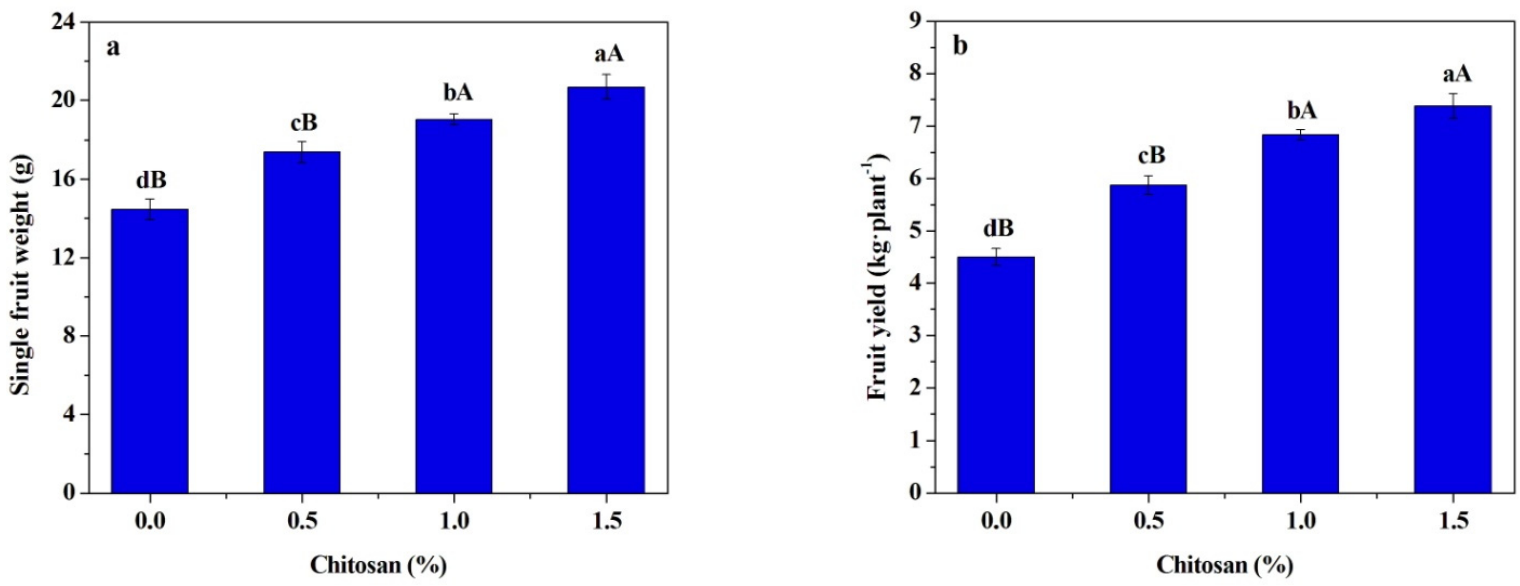

Figure 3. The effects of chitosan on single fruit weight (a) and fruit yield (b) of $R$. roxburghii. Values and error bars indicate the mean and SD of three replicates, respectively. Different small and capital letters indicate significant differences at $5 \%$ level $(p<0.05)$ and $1 \%$ level $(p<0.01)$, respectively. 
The effects of chitosan on the quality of $R$. roxburghii fruits are shown in Table 3. The vitamin $C$, soluble solid, soluble sugar, total acidity, soluble protein, flavonoids, and SOD activity of $R$. roxburghii fruits increased gradually with the increase in chitosan concentration. A total of $0.5 \sim 1.5 \%$ chitosan significantly $(p<0.05)$ improved vitamin $C$, soluble solid, soluble sugar, total acidity, soluble protein, flavonoids, and SOD activity of $R$. roxburghii, which effectively increased by 9.82 34.97\%, 9.96 21.58\%, 11.55 37.62\%, 17.07 52.44\%, $6.32 \sim 20.59 \%, 12.12 \sim 31.19 \%$, and $9.99 \sim 20.86 \%$ compared to non-spray chitosan, respectively. The abovementioned findings indicate that the foliar application of the appropriate chitosan concentration could effectively improve the fruit quality of $R$. roxburghii.

Table 3. The effects of chitosan on quality of $R$. roxburghii fruits.

\begin{tabular}{|c|c|c|c|c|c|c|c|}
\hline $\begin{array}{c}\text { Chitosan } \\
(\%)\end{array}$ & $\begin{array}{l}\text { Vitamin C } \\
\left(\mathrm{mg} \cdot \mathrm{g}^{-1}\right)\end{array}$ & $\begin{array}{c}\text { Soluble Solid } \\
(\%)\end{array}$ & $\begin{array}{c}\text { Soluble Sugar } \\
(\%)\end{array}$ & $\begin{array}{c}\text { Total Acidity } \\
(\%)\end{array}$ & $\begin{array}{c}\text { Soluble } \\
\text { Protein }(\%)\end{array}$ & $\begin{array}{l}\text { Flavonoids } \\
\left(\mathrm{mg} \cdot \mathrm{g}^{-1}\right)\end{array}$ & $\begin{array}{l}\text { SOD Activity } \\
\left(\mathrm{U} \cdot \mathrm{g}^{-1} \mathrm{FW}\right)\end{array}$ \\
\hline 0 & $17.83 \pm 1.12^{\mathrm{d}}$ & $10.24 \pm 0.11^{\mathrm{d}}$ & $3.03 \pm 0.12^{\mathrm{d}}$ & $2.46 \pm 0.11^{\mathrm{d}}$ & $12.82 \pm 0.66^{\mathrm{d}}$ & $0.095 \pm 0.005^{c}$ & $373.61 \pm 6.91^{\mathrm{d}}$ \\
\hline 0.5 & $19.59 \pm 1.09^{c}$ & $11.26 \pm 0.25^{c}$ & $3.38 \pm 0.08^{c}$ & $2.88 \pm 0.10^{c}$ & $13.63 \pm 0.55^{c}$ & $0.106 \pm 0.005^{\mathrm{cb}}$ & $410.95 \pm 4.42^{c}$ \\
\hline 1.0 & $22.31 \pm 0.52^{b}$ & $12.08 \pm 0.24^{a}$ & $3.84 \pm 0.12^{b}$ & $3.43 \pm 0.13^{\mathrm{ab}}$ & $14.75 \pm 0.62^{b}$ & $0.115 \pm 0.005^{b}$ & $437.78 \pm 6.25^{b}$ \\
\hline 1.5 & $24.07 \pm 1.33^{\mathrm{a}}$ & $12.45 \pm 0.33^{a}$ & $4.17 \pm 0.13^{\mathrm{a}}$ & $3.75 \pm 0.11^{\mathrm{a}}$ & $15.46 \pm 0.39^{a}$ & $0.125 \pm 0.013^{a}$ & $451.55 \pm 6.11^{a}$ \\
\hline
\end{tabular}

Values indicate the mean \pm SD of three replicates. Different small letters indicate significant differences at $5 \%$ level $(p<0.05)$.

\section{Discussion}

Numerous findings have been documented that chitosan shows excellent efficacy in reducing disease incidence and can be used as an elicitor of plants' natural defense response [30-34]. For example, Zhang et al. [30] indicated that the foliar application of $0.2 \sim 0.4 \mathrm{~g} \cdot \mathrm{L}^{-1}$ chitosan effectively controlled the soft rot of kiwifruit with the control effect of $71.94 \sim 82.13 \%$. The results here exhibit that the foliar application of $0.5 \sim 1.5 \%$ chitosan significantly $(p<0.01)$ reduced the incidence rate and disease index of Sphaerotheca sp. in $R$. roxburghii. The inducing control effect of 1.0 1.5\% chitosan against Sphaerotheca sp. was $69.30 \sim 72.87 \%$. The suitable effects probably derive from its dual modes of action, that it suppresses pathogen entrance, colonization, and growth, as well as induces the $R$. roxburghii plant defense responses $[29,30,35,36]$. However, the incidence rate, disease index, and control effect were not significant between 1.0\% chitosan and 1.5\% chitosan treatments, which might be related to the dose effect of chitosan.

The previous studies have also shown that the foliar application of chitosan induces the synthesis of flavonoids, polyphenolics, and lignin in plants enhances the content of sugar and proline, boosts the defense enzyme activity of the plant [22,24]. Proline and soluble sugar are important substances in regulating cell permeability. In this study, the foliar application of $0.5 \sim 1.5 \%$ chitosan effectively increased proline and soluble sugar of leaves in $R$. roxburghii. These results show that the application of chitosan effectively adjusted osmotic pressure in the cells by increasing proline and soluble sugar of leaves in $R$. roxburghii and could improve the resistance of plants to stress such as disease and drought. MDA is an important indicator for the intensity of membrane lipid peroxidation, and flavonoids are an important disease-resistant substance. The results presented here demonstrate that the foliar application of $1.0 \sim 1.5 \%$ chitosan significantly $(p<0.01)$ reduced the MDA content of leaves in $R$. roxburghii and increased its flavonoids, indicating the chitosan application alleviated the membrane lipid peroxidation and promoted the disease resistance of $R$. roxburghii plants. PPO catalyzes phenolic substances to synthesize lignin, strengthen the cell wall structure and avoid entrance and colonization of phytopathogens toward plants [20]. SOD is responsible for eliminating reactive oxygen species to avoid plants from oxidative stress during phytopathogen invasion [20,37]. In this study, the foliar application of $0.5 \sim 1.5 \%$ chitosan significantly $(p<0.01)$ enhanced SOD and PPO activities of leaves in $R$. roxburghii, further evidencing the chitosan application enhanced the disease resistance of $R$. roxburghii plants.

Photosynthesis is the physiological basis of plant growth and yield. Chitosan can increase the plant yield substantially by improving the photosynthetic rate by enhancing 
the stomatal function and chlorophyll content [19]. Chitosan also can be used as a plant growth promoter to enhance the division of root cells by activating the plant auxin and cytokinin signal transduction, gene expression, which increases the nutrient intake and enhance the plant growth $[19,38]$. The present results indicate that the foliar application of $0.5 \sim 1.5 \%$ chitosan effectively enhanced the photosynthetic rate, the content of chlorophyll $\mathrm{a}$, chlorophyll $\mathrm{b}$, and chlorophyll $\mathrm{a}+\mathrm{b}$ of $R$. roxburghii leaves compared with control plants, as well as significantly $(p<0.01)$ increased single fruit weight and fruit yield of R. roxburghii. Moreover, the foliar application of $0.5 \sim 1.5 \%$ chitosan significantly $(p<0.05)$ improved vitamin C, soluble solid, soluble sugar, total acidity, soluble protein, flavonoids, and SOD activity of R. roxburghii, which effectively increased by $9.82 \sim 34.97 \%, 9.96 \sim 21.58 \%$, $11.55 \sim 37.62 \%, 17.07 \sim 52.44 \%$, 6.32 20.59\%, 12.12 31.19\%, and 9.99 20.86\% compared to non-spray chitosan, respectively. Generally, the greater the chlorophyll a/b value, the stronger plants have stress resistance. Chlorophyll a/b value of $R$. roxburghii treated by chitosan also shows that the foliar application of $0.5 \sim 1.5 \%$ chitosan effectively improved the stress resistance of $R$. roxburghii. The findings here imply that the foliar application of $0.5 \sim 1.5 \%$ chitosan could reliably decrease the occurrence of Sphaerotheca sp. in R. roxburghii and induce systemic resistance, thereby enhancing the photosynthesis, growth, yield, and quality of $R$. roxburghii.

Chitosan is a natural macromolecule compound with antibacterial, nontoxic, antioxidant, renewable, biocompatible, and biodegradable advantages. The food safety risks caused by chitosan are almost nonexistent $[19,20,39]$. Zhang et al. [30] indicated that the foliar application of $0.2 \sim 0.4 \mathrm{~g} \cdot \mathrm{L}^{-1}$ chitosan effectively reduced the incidence of soft rot, and notably enhanced the yield and quality, and prolonged the shelf life of kiwifruit. Mondal et al. [40] found that the foliar application of chitosan at $100 \mathrm{ppm}$ may be used at the early growth stage for getting maximum seed yield in maize. Lei et al. [41] reported that the foliar application of $100 \mathrm{mg} \cdot \mathrm{L}^{-1}$ chitosan improved artemisinin biosynthesis in A. annua. This work highlights that chitosan can be used as an ideal inductor to control Sphaerotheca sp. of $R$. roxburghii and enhance the photosynthesis, growth, yield, and quality of $R$. roxburghii, and 1.0 1.5\% chitosan is a green, safe, efficient, and suitable concentration. In order to fully understand the inducing control mechanism of chitosan on Sphaerotheca sp. of $R$. roxburghii, future researches are essential about the effects of chitosan on the cell growth, cell structure, and disease resistance gene expression of Sphaerotheca sp., etc.

\section{Conclusions}

In conclusion, the present study indicates that the foliar application of 1.0 1.5\% chitosan had a suitable inducing control effect against Sphaerotheca sp. in R. roxburghii and effectively increased proline, soluble sugar, flavonoids, SOD, and POD activities of leaves in $R$. roxburghii and reduced its MDA content. Moreover, the foliar application of 1.0 1.5\% chitosan reliably enhanced the photosynthetic rate and chlorophyll content of $R$. leaves in roxburghii, as well as improved the yield and quality of $R$. roxburghii fruits. This study highlights that chitosan can be used as an ideal inductor to control Sphaerotheca sp. of $R$. roxburghii and enhance the growth, yield, and quality of $R$. roxburghii.

Author Contributions: X.W. and H.A. constructed the project; X.W., H.A. and J.L. designed the experiments; J.L., Z.G. and Y.L. performed the experiments; J.L. and Z.G. analyzed the data; J.L. and X.W. wrote the paper. All authors have read and agreed to the published version of the manuscript.

Funding: This work was supported by the Joint Fund of the National Natural Science Foundation of China and the Karst Science Research Center of Guizhou Province (no. U1812401), the National Natural Science Foundation of China (no. 32160656), the Science-Technology Support Program of Guizhou Province (no. (2019)2407, (2020)1Y134, (2021)YB243), the “Hundred" Level Innovative Talent Foundation of Guizhou Province (no. 20164016), and the Cultivation Program of Guizhou University (no. (2019)09).

Data Availability Statement: The datasets during or analyzed during the current study available from the corresponding author on reasonable request. 
Conflicts of Interest: We declare that we do not have any commercial or associative interest that represents a conflict of interest in connection with the work submitted.

\section{References}

1. Wang, L.T.; Lv, M.J.; An, J.Y.; Fan, X.H.; Dong, M.Z.; Zhang, S.D.; Wang, J.D.; Wang, Y.Q.; Cai, Z.H.; Fu, Y.J. Botanical Characteristics, Phytochemistry and Related Biological Activities of Rosa roxburghii Tratt Fruit, and Its Potential Use in Functional Foods: A Review. Food Funct. 2021, 12, 4. [CrossRef]

2. Qi, L.L.; Zhou, R.L. The Healthcare Function and Development Trend of Toxburgh Rose. Food Res. Dev. 2016, 37, $212-214$.

3. Wang, D.J.; Lu, M.; Ludlow, R.A.; Zeng, J.W.; Ma, W.T.; An, H.M. Comparative Ultrastructure of Trichomes on Various Organs of Rosa roxburghii. Microsc. Res. Tech. 2021, 84, 1-9. [CrossRef]

4. Liu, X.Z.; Zhao, H.B.; Li, Y.F.; Yu, Z.H.; Liu, X.H.; Huang, M.Z. Identification and Oenological Properties Analysis of a Strain of Hanseniaspora uvarum from Rosa roxburghii. Food Ferment. Ind. 2020, 46, 97-104.

5. Huang, X.; Yan, H.; Zhai, L.; Yang, Z.; Yi, Y. Characterization of the Rosa roxburghii Tratt Transcriptome and Analysis of MYB Genes. PLoS ONE 2019, 14, e0203014. [CrossRef]

6. Hao, M.H.; Zhang, F.; Liu, X.X.; Zhang, F.; Wang, L.J.; Xu, S.J.; Zhang, J.H.; Ji, H.L.; Xu, P. Qualitative and Quantitative Analysis of Catechin and Quercetin in Flavonoids Extracted from Rosa roxburghii Tratt. Trop. J. Pharm. Res. 2018, 17, 71-76. [CrossRef] [PubMed]

7. Xu, P.; Liu, X.; Xiong, X.; Zhang, W.; Cai, X.; Qiu, P.; Hao, M.; Wang, L.; Lu, D.; Zhang, X.; et al. Flavonoids of Rosa roxburghii Tratt Exhibit Anti-Apoptosis Properties by Regulating PARP-1/AIF. J. Cell Biochem. 2017, 118, 3943-3952. [CrossRef] [PubMed]

8. Chen, Y.; Liu, Z.J.; Liu, J.; Liu, L.K.; Zhang, E.S.; Li, W.L. Inhibition of Metastasis and Invasion of Ovarian Cancer Cells by Crude Polysaccharides from Rosa roxburghii Tratt In Vitro. Asian Pac. J. Cancer Prev. 2014, 15, 10351-10354. [CrossRef]

9. Fan, W.G.; Pan, X.J.; Chen, H.; Yang, H.R.; Gomg, F.F.; Guan, J.Y.; Wang, M.L.; Mu, R. Effects of Oxalic Acid on the Nutrient of Calcareous Cultivated Soil and Leaf, Fruit Yield and Quality of Rosa roxburghii Tratt. J. Fruit Sci. 2021, 38, 1113-1122. [CrossRef]

10. Han, L.; Liu, X.D.; Huang, W.Y.; Wu, X.M. Occurrence and Control Technology of Powdery Mildew in Rose roxburgh Tratt. China Fruits 2021, 1, 6-10. [CrossRef]

11. Yan, K.; Wang, J.L.; Zhou, Y.; Fu, D.P.; Huang, R.M. Efficacy of Five Fungicidesin Rosa roxburghii Tratt against Sphaerotheca Sp. Agrochemicals 2018, 57, 609-610.

12. Meena, R.S.; Kumar, S.; Datta, R.; Lal, R.; Vijayakumar, V.; Brtnicky, M.; Marfo, T.D. Impact of Agrochemicals on Soil Microbiota and Management: A Review. Land 2020, 9, 34. [CrossRef]

13. Wang, Q.; Zhang, C.; Long, Y.; Wu, X.; Su, Y.; Lei, Y.; Ai, Q. Bioactivity and Control Efficacy of the Novel Antibiotic Tetramycin Against Various Kiwifruit Diseases. Antibiotics 2021, 10, 289. [CrossRef] [PubMed]

14. Massi, F.; Torriani, S.; Borghi, L.; Toffolatti, S. Fungicide Resistance Evolution and Detection in Plant Pathogens: Plasmopara viticola as a Case Study. Microorganisms 2021, 9, 119. [CrossRef] [PubMed]

15. Vlot, A.C.; Sales, J.H.; Lenk, M.; Bauer, K.; Brambilla, A.; Sommer, A.; Nayem, S. Systemic Propagation of Immunity in Plants. New Phytol. 2020, 229, 1234-1250. [CrossRef]

16. Lopez-Moya, F.; Suarez-Fernandez, M.; Lopez-Llorca, L.V. Molecular Mechanisms of Chitosan Interactions with Fungi and Plants. Int. J. Mol. Sci. 2019, 20, 332. [CrossRef]

17. Yan, K.; Luo, Z.L.; Hu, F.L.; Wu, T.H.; Tian, H.S.; Huang, R.M.; Yan, J.C. Ascorbic Acid 6\% AS Inducing Resistance against Sphaerotheca Sp. in Rosa roxburghii Tratt. Agrochemicals 2017, 56, 528-530. [CrossRef]

18. Verlee, A.; Mincke, S.; Stevens, C.V. Recent Developments in Antibacterial and Antifungal Chitosan and Its Derivatives. Carbohyd. Polym. 2017, 164, 268-283. [CrossRef]

19. Chakraborty, M.; Hasanuzzaman, M.; Rahman, M.; Khan, M.; Bhowmik, P.; Mahmud, N.U.; Tanveer, M.; Islam, T. Mechanism of Plant Growth Promotion and Disease Suppression by Chitosan Biopolymer. Agriculture 2020, 10, 624. [CrossRef]

20. Torres-Rodriguez, J.A.; Reyes-Pérez, J.J.; Castellanos, T.; Angulo, C.; Hernandez-Montiel, L.G. A Biopomyler with Antimicrobial Properties and Plant Resistance Inducer Against Phytopathogens: Chitosan. Not. Sci. Biol. 2021, 49, 1-15. [CrossRef]

21. Wang, B.; Zhang, S.; Wang, X.; Yang, S.; Jiang, Q.; Xu, Y.; Xia, W. Transcriptome Analysis of the Effects of Chitosan on the Hyperlipidemia and Oxidative Stress in High-Fat Diet Fed Mice. Int. J. Biol. Macromol. 2017, 102, 104-110. [CrossRef]

22. Xoca-Orozco, L.Á.; Cuellar-Torres, E.A.; Gonz á lez-Morales, S.; Gutiérrez-Martínez, P.; López-Garcí, U.; Herrera-Estrella, L.; Vega-Arreguín, J.; Chacón-López, A. Transcriptomic Analysis of Avocado Hass (Persea americana Mill) In the Interaction System Fruit-Chitosan-Colletotrichum. Front. Plant Sci. 2017, 8, 956. [CrossRef]

23. Rahman, M.; Mukta, J.A.; Sabir, A.A.; Gupta, D.R.; Mohi-ud-din, M.; Hasanuzzaman, M.; Miah, M.G.; Rahman, M.; Islam, M.T. Chitosan Biopolymer Promotes Yield and Stimulates Accumulation of Antioxidants in Strawberry Fruit. PLoS ONE 2018, 13, e0203769. [CrossRef]

24. Emami Bistgani, Z.; Siadat, S.A.; Bakhshandeh, A.; Ghasemi Pirbalouti, A.; Hashemi, M. Interactive Effects of Drought Stress and Chitosan Application on Physiological Characteristics and Essential Oil Yieldof Thymus daenensis Celak. Crop J. 2017, 5, 407-415. [CrossRef]

25. Coutinho, T.C.; Ferreira, M.C.; Rosa, L.H.; de Oliveira, A.M.; de Oliveira Júnior, E.N. Penicillium citrinum and Penicillium mallochii: New Phytopathogens of Orange Fruit and Their Control Using Chitosan. Carbohyd. Polym. 2020, 234, 115918. [CrossRef] 
26. El Amerany, F.; Meddich, A.; Wahbi, S.; Porzel, A.; Taourirte, M.; Rhazi, M.; Hause, B. Foliar Application of Chitosan Increases Tomato Growth and Influences Mycorrhization and Expression of Endo-Chitinase-Encoding Genes. Int. J. Mol. Sci. 2020, 21, 535. [CrossRef]

27. Berger, L.R.R.; Stamford, N.P.; Willadino, L.G.; Laranjeira, D.; de Lima, M.A.B.; Malheiros, S.M.M.; Stamford, T.C.M. Cowpea Resistance Induced Against Fusarium oxysporum f. Sp. tracheiphilum by Crustaceous Chitosan and by Biomass and Chitosan Obtained from Cunninghamella elegans. Biol. Control 2016, 92, 45-54. [CrossRef]

28. Obianom, C.; Romanazzi, G.; Sivakumar, D. Effects of Chitosan Treatment on Avocado Postharvest Diseases and Expression of Phenylalanine Ammonia-Lyase, Chitinase and Lipoxygenase Genes. Post. Biology Tech. 2019, 147, 214-221. [CrossRef]

29. Zhang, C.; Long, Y.H.; Wang, Q.P.; Li, J.H.; An, H.M.; Wu, X.M.; Li, M. The Effect of Preharvest 28.6\% Chitosan Composite Film Sprays for Controlling Soft Rot on Kiwifruit and Its Defense Responses. Hortic. Sci. 2019, 46, 180-194. [CrossRef]

30. Zhang, C.; Long, Y.H.; Li, J.H.; Li, M.; Xing, D.K.; An, H.M.; Wu, X.M.; Wu, Y.Y. A Chitosan Composite Film Sprayed before Pathogen Infection Effectively Controls Postharvest Soft Rot in Kiwifruit. Agronomy 2020, 10, 265. [CrossRef]

31. El-Mohamedya, R.S.R.; Abd El-Aziz, M.E.; Kamel, S. Antifungal Activity of Chitosan Nanoparticles against Some Plant Pathogenic Fungi In Vitro. Agric. Eng. Int. CIGR J. 2019, 21, 201-209.

32. Farag, S.M.A.; Elhalag, K.M.A.; Mohamed, H.; Hagag, M.H.; Khairy, A.S.M.; Ibrahim, H.M.; Saker, M.T.; Messiha, N.A.S. Potato Bacterial Wilt Suppression and Plant Health Improvement after Application of Different Antioxidants. J. Phytopathol. 2017, 65, 522-537. [CrossRef]

33. Fan, Z.; Qin, Y.; Liu, S.; Xing, R.; Yu, H.; Li, P. Chitosan Oligosaccharide Fluorinated Derivative Control Root-Knot Nematode (Meloidogyne incognita) Disease Based on the Multi-Efficacy Strategy. Mar. Drugs. 2020, 18, 273. [CrossRef]

34. Liang, W.L.; Yu, A.X.; Wang, G.D.; Zheng, F.; Hu, P.T.; Jia, J.L.; Xu, H.H. A Novel Water-Based Chitosan-La Pesticide Nanocarrier Enhancing Defense Responses in Rice (Oryza sativa L.) Growth. Carbohyd Polym. 2018, 199, 437-444. [CrossRef]

35. Xing, K.; Zhu, X.; Peng, X.; Qin, S. Chitosan Antimicrobial and Eliciting Properties for Pest Control in Agriculture: A Review. Agron. Sustain. Dev. 2015, 35, 569-588. [CrossRef]

36. Li, P.; Cao, Z.; Wu, Z.; Wang, X.; Li, X. The Effect and Action Mechanisms of Oligochitosan on Control of Stem Dry Rot of Zanthoxylum bungeanum. Int. J. Mol. Sci. 2016, 17, 1044. [CrossRef] [PubMed]

37. Shi, Z.J.; Wang, F.; Lu, Y.Y.; Deng, J. Combination of Chitosan and Salicylic Acid to Control Postharvest Green Mold Caused by Penicillium digitatum in Grapefruit Fruit. Sci. Hortic. 2018, 223, 54-60. [CrossRef]

38. Dzung, N.A.; Khanh, V.T.P.; Dzung, T.T. Research on Impact of Chitosan Oligomers on Biophysical Characteristics, Growth, Development and Drought Resistance of Coffee. Carbohydr. Polym. 2011, 84, 751-755. [CrossRef]

39. Wang, Q.; Zhang, C.; Wu, X.; Long, Y.; Su, Y. Chitosan Augments Tetramycin Against Soft Rot in Kiwifruit and Enhances Its Improvement for Kiwifruit Growth, Quality and Aroma. Biomolecules 2021, 11, 1257. [CrossRef]

40. Mondal, M.; Puteh, A.B.; Dafader, N.C.; Rafii, M.Y.; Malek, M.A. Foliar Application of Chitosan Improves Growth and Yield in Maize. J. Food Agric. Environ. 2013, 11, 520-523.

41. Lei, C.; Ma, D.; Pu, G.; Qiu, X.; Du, Z.; Hong, W.; Li, G.; Ye, H.; Liu, B. Foliar Application of Chitosan Activates Artemisinin Biosynthesis in Artemisia annua L. Ind. Crop. Prod. 2011, 33, 176-182. [CrossRef] 